\title{
Exploring Strategic Directions for the Local Innovation Ecosystem Development in the Mining Industry
}

\author{
Yuliia Lazarenko ${ }^{1, *}$, Olga Garafonova ${ }^{1}$, Vyktoriia Marhasova ${ }^{2}$, Nataliia Tkalenko $^{3}$, and \\ Svetlana Grigashkina ${ }^{4}$ \\ ${ }^{1}$ Kyiv National Economic University named after Vadym Hetman, Management Department, 03057, \\ 54/1 Pr. Peremogy, Kyiv, Ukraine \\ ${ }^{2}$ Chernihiv National University of Technology, Accounting, Tax and Audit Department, 14035 \\ Chernihiv, Ukraine \\ ${ }^{3}$ Chernihiv National University of Technology, Public Administration and Business Management \\ Department, 14035 Chernihiv, Ukraine \\ ${ }^{4}$ T. F. Gorbachev Kuzbass State Technical University, 650000, 28 Vesennyaya St., Kemerovo, Russia
}

\begin{abstract}
The paper is aimed to provide a deeper understanding of the core components of the local innovation ecosystem in the mining industry, including the role of the main actors related to the development and commercialization of innovation in the sector, such as mining operators, technology suppliers and service providers, research and development institutions, local communities, governments and policymakers. As a result of the study, a set of recommendations is presented which focused on the strategic directions that should be taken into consideration in order to develop an effective and efficient local innovation ecosystem and enhance the level and quality of innovation in the industry.
\end{abstract}

\section{Introduction}

The global knowledge-based economy is driven by innovation, accordingly creating favourable environments for innovative businesses has become over the last years one of the top industrial policy priorities in developed countries. However, existing approaches to development strategies that support innovative enterprises are proving ineffective and insufficient. As a result, the concept of the innovation ecosystem has emerged that is especially relevant in the networked economy given the growing trend towards open innovation collaboration and strategic partnership. The systems approach is used to describe the multifaceted nature of the innovation process at various levels - local, regional, national, and global and explain the interrelationship between the key actors of an innovation network.

\footnotetext{
*Corresponding author: yuliia.lazarenko@kneu.ua
} 
A local innovation ecosystem can be defined as a place-based community of interacting actors that are involved in the innovation process as well as support innovation-oriented activities, along with the infrastructure and cross-organizational enabling conditions which allow them to develop and adopt solutions to local challenges [1]. According to the approach proposed by O. Granstrand and M. Holgersson (2020), an innovation ecosystem comprises not only actors and a set of activities, but also artifacts, (i.e. innovative products and services, tangible and intangible resources, and other types of system inputs and outputs), as well as the institutions and interactions among them, including complementary (collaborative) and substitute (competitive) relations, that are important for achieving strong innovation performance [2]. Dynamic balancing of value creation across complements, complementors, collaborating competitors, and consumers, and value sharing among all the actors are in this regard essential for building and maintaining a wellperforming innovation ecosystem.

This research focuses on defining a theoretical basis for a deeper understanding of the key elements and specific characteristics of the local innovation ecosystem in the mining sector and is intended to identify strategic directions that should be taken into consideration in order to develop a productive innovation ecosystem and enhance the innovation performance in the industry.

\section{Materials and Methods}

It had been shown that innovation ecosystems provide the means to maintain economic stability, develop investment opportunities, and enable information flows and resource sharing in the sector. In the modern business reality for many mining executives innovation has become an essential part of the corporate strategy. Many industry companies are currently focused on business improvement initiatives and adopt different innovation programs in order to get long-term cost advantages or enhance operational flexibility. But as evidence shows, most companies of the mining sector still tend to operate in isolation, relying on their own innovation capacity, and the long-term mindset as well as planning towards strategic innovation collaboration necessary to achieve significant improvements in the industry, is limited. Industry companies often have difficulty spreading their risks and are less likely to adopt transformational technology-based innovations in-house, but these difficulties could be addressed through a local innovation ecosystem. To minimize the barriers to innovation performance, mining operators and the broader ecosystem of industry participants would benefit from acting together in cooperation to promote and foster innovation.

This paper presents a theoretical framework for investigating the main elements of the innovation ecosystem in the mining sector and strives to provide a conceptual basis for defining the strategic directions which are important for effectively managing an innovation network and building a well-functioning local innovation ecosystem.

\section{Results and Discussion}

From a theoretical viewpoint, the innovation ecosystem encompasses the network of interactions between individuals, organizations, institutions and their environment, that aim at developing new technologies, promoting innovation and entrepreneurship, and therefore can be defined as a product of three core elements: the surrounding business environment and investment climate, its interacting actors and the evolving entrepreneurial culture that determines attitude towards risk-taking, willingness to change and innovation performance in general [3]. In this context "actors" include the researchers, entrepreneurs, investors and 
other individuals doing innovation as well as such organizations as universities, research and development centers, innovative businesses, industry players, venture capitalists, institutional funders, local communities, knowledge networks, etc. that provide specific innovation-oriented activities. Following the approach proposed by A. Aaltonen (2016), five types of actors can be distinguished which are necessary to build a strong innovation ecosystem: entrepreneurs and potential entrepreneurs who may have the skills and capabilities required for innovative entrepreneurship, private investors and venture capitalists that look for the opportunities to invest in the most promising businesses, large corporations which fund entrepreneurial ventures and spin off new companies, universities and research institutions that provide assistance in technical issues and policymakers which create sufficient framework conditions that enable innovators to benefit from their activity and make positive contributions to the social and economic well-being of a region, maintain local communities and knowledge networks as well as shape the regional dynamics [4].

Adopting a multidimensional integrated approach to understanding the nature of the innovation ecosystem in the mining sector, we share the opinion that it can be considered as a complex system that embraces interconnected and synergistic sub-ecosystems: science, technology, and business ecosystems [5]. In this context the science dimension refers to a subsystem that generates scientific knowledge, the technology dimension focuses on applied technology and creates industrial knowledge, and the business dimension involves innovative products, services, and managerial decisions, the implementation of which contributes to value propositions. In addition to these core dimensions, we consider it appropriate to highlight the information subsystem that needs particular attention in view of the fact that nowadays information and digital technologies have become an essential part of the mining supply chain [6]. The information subsystem in this regard includes information and communication management systems, digital platforms, and related services. With reference to the summarized literature, the main subsystems of the innovation ecosystem can be presented (Figure 1), which are developed by the authors adapting $[1 ; 5-6]$.

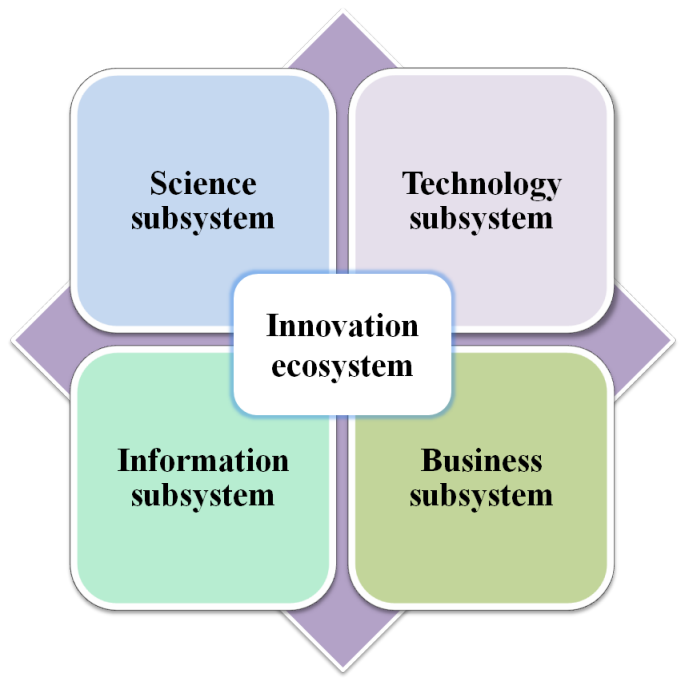

Fig. 1. The core structural subsystems of the innovation ecosystem.

It is necessary to emphasize that the surrounding business environment or crossorganizational enabling conditions for innovation, including education, training and mentorship programs, as well as resilient infrastructure (e.g. information and communication technologies within the information subsystem) are particularly relevant for 
building and maintaining productive innovation ecosystem. Research organizations, universities and their technology transfer offices have a huge impact on the industry companies. In particular, these organizations can offer technical support and validation to innovative businesses, provide them with necessary equipment and services as well as the associated technical expertise. Support organizations such as startup incubators and accelerators are also important to stimulate innovation as they are able to link technology, capital and know-how to accelerate the development of new companies and speed the exploitation of technology. In addition, they provide the different support services among which mentorship has proven to be the key [7]. Critical to the above-mentioned enabling conditions is how well they link and align incentives of the key actors of an ecosystem and their activities. Although entrepreneurs and industry companies are essentially at the centre of any local innovation ecosystem it is important to underline that all its stakeholders need to operate together to reach success and achieve innovation performance.

According to D. Isenberg (2011), the innovation system comprises six main domains which are linked and interrelated in complex ways: a conducive culture, enabling policies, leadership and regulatory framework, availability of appropriate finance capital, quality human capital, venture friendly markets for products and a range of institutional supports, e.g. legal, accounting, technical and advisory services [8; 9]. By studying models developed abroad and summarizing the international experiences, the following key elements of an effective innovation ecosystem can be outlined: an entrepreneurial culture, which should reflect a shift towards more collaborative open innovation; leaders or "champions", i.e. successful entrepreneurs and corporations which can drive the ecosystem by working with other stakeholders and hence accelerate the innovation-oriented activities; stakeholders engagement and network collaboration tools that enable entrepreneurs, mentors, service providers and investors to share ideas and knowledge, facilitate access to required resources, receive encouragement and expand their opportunities; learning accelerants, i.e. programs which are aimed at supporting regionally based innovative businesses as well as physical space that is considered as a necessary precondition for sharing information, building a community, and fostering a favourable innovation climate [10; 11].

The innovation activity of the mining sector comes with diversity as providers compete across different technologies and customers. There is an integrated industrial innovation ecosystem within the mining industry that accounts for much of its innovation capacity in comparison with the mining operators themselves. The innovation performance in the mining industry relies on the conducive innovation ecosystem. The sustainable development of this system and effective collaboration between its stakeholders is therefore important for the whole industry. Mining companies should play a significant role in shaping the new industrial innovation ecosystem within the sector - rather than being passive actors of the innovation process, they need to integrate all the elements in order to capture the value of innovation across the network. All the actors contribute to the sustainability and effectiveness of the industrial innovation ecosystem which provides mutual benefits and profitable outcomes for both individual players, such as industry suppliers, service providers, start-ups, research and development institutions, asset owners, as well as for the local communities and society as a whole. Given the nature of the mining industry and sectoral specificities, among the ecosystem actors particular mention should be made of the largest industry companies that have significant financial resources and strategic influence they can exert at micro, meso and macro levels over the key elements of the innovation process. Large mining companies are typically characterized as being conservative and inflexible regarding issues relating to the development and implementation of radical innovation within the sector, they tend to avoid the risks and have a traditional restrictive mindset which discourages significant organizational changes. 
Service companies play another important role in maintaining the sectoral innovation ecosystem by acting as technology suppliers into miner operators. Providing effective interaction between the service operators and mining companies can ensure feedback and proper functioning of the industry innovation ecosystem as well as the integration of all its elements. Small technology suppliers and service providers often emerge as start-ups and university spin-offs and are founded primarily with the aim to strengthen the links between the mining industry and science and are intended to bring new technologies and decisions to the market. However, they often lack a clear view of what technology is required within a sector, appropriate technical expertise and ability to identify risks as well as sufficient financial resources, and therefore such entities often do not get the necessary support to implement their creative ideas. According to the findings of industry research study, the lack of needs-based visibility and insufficient funding are the major factors that hinder the appropriate operating and maintaining the sectoral ecosystem and slow the flow of research-based innovation into the mining industry [12].

Representation of the main actors of the local innovation ecosystem in the mining sector is shown in Figure 2 that is developed by the authors adapting [1; 4-6; 13-16].

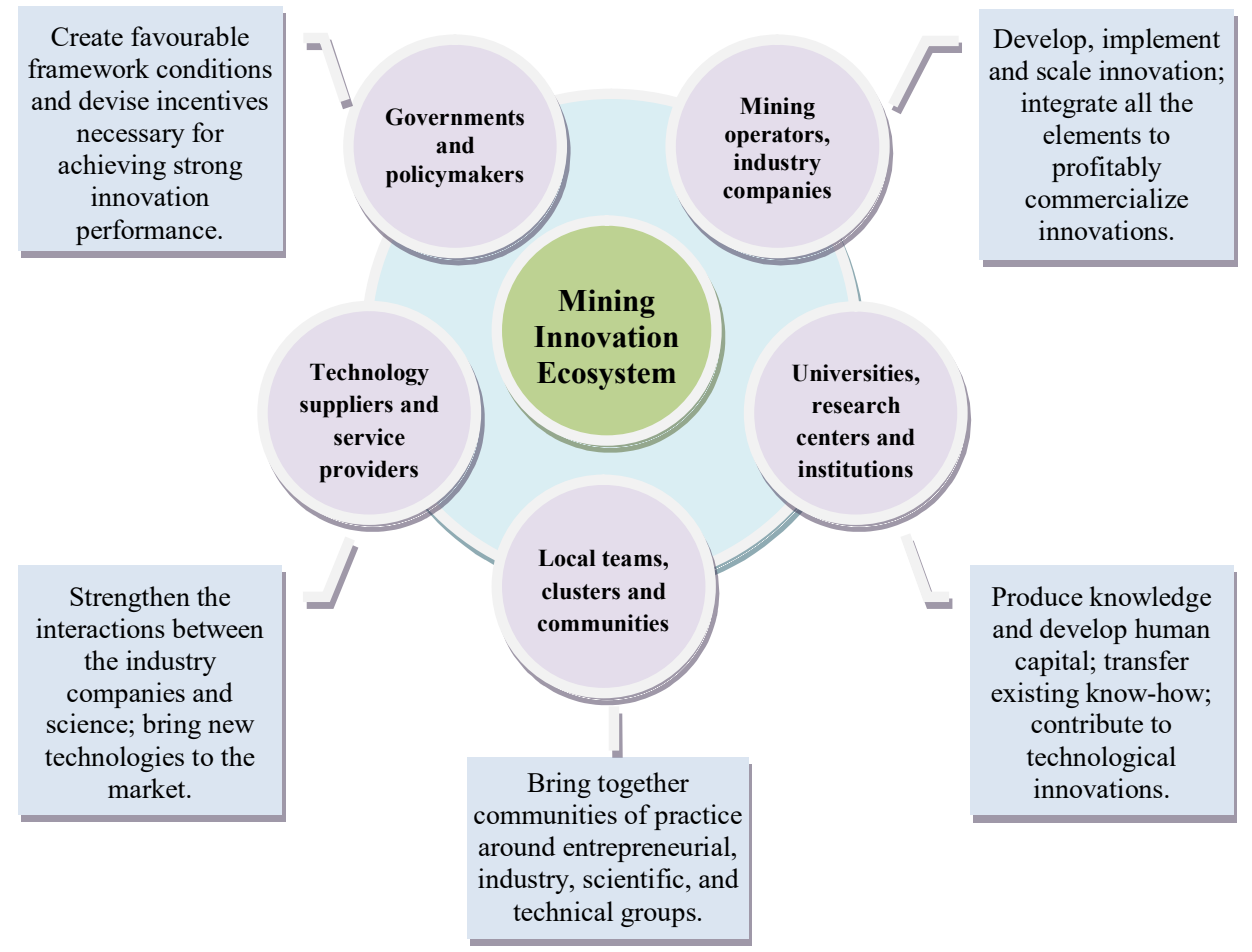

Fig. 2. Representation of the main actors of the local innovation ecosystem in the mining sector.

A successful innovation ecosystem in the mining sector requires the different actors to play their part, combining to create the innovation incentives and risk-sharing mechanisms for the long-term strategic partnership. As empirical evidence shows, public institutions such as universities and research institutions have always played a critical role in the economy-wide innovation processes. However, nowadays the biggest global universities and research centers that deal with the innovation activity issues of mining operators are not as involved in the innovation development of the sector as they could be [12]. Building collaborative relationships between businesses, universities and research centers, involving 
local communities, enhancing transparency and communication within the innovation ecosystem will enable development of new business capabilities and improvement of innovation performance in mining. Governments and policymakers which create favourable framework conditions necessary for achieving strong innovation performance and make positive contributions to the social and economic well-being of a region, can for their part encourage innovation in the industry and have the capacity to influence the evolution and maintaining of the innovation ecosystem in the mining sector.

According to the industry analysis report the main common attributes of the industry innovation ecosystem can be highlighted: a long-term vision, long-term partnerships, leadership by biggest companies of the sector, high investment in research-oriented activities, collaborative interactions with universities and research institutions, innovation openness and aggressive competition between companies within the industry is largely based on cost rather than technology-based innovation [12].

Targeted partnerships, strategic collaborative relationships, and networked interactions create the necessary flow of resources within the innovation ecosystem. But there are industry factors that constrain the effective forming and maintaining of sectoral strategic partnerships. Thus, collaborative projects with key technology suppliers and service providers might fail due to contradictory interests and priorities of the partners or poorly coordinated objectives of both sides. One of the main challenges facing mining companies when considering issues and adopting decisions on strategic collaboration that involves active participation with other organizations within the ecosystem in joint innovation projects is the risk of information leakage and losing proprietary knowledge [12].

It is possible to summarize the major impediments to productive innovation partnerships and effective strategic collaborative relationships between the key actors of the industry innovation ecosystem: insufficient understanding of each other's business models and the peculiarities of innovation processes, lack of alignment between organizational strategies and innovation goals, constraints on sharing information and knowledge with partners due to lack of trust, as well as diverging interests, priorities, and values of various stakeholders.

\section{Conclusion}

Thus, from a region's economic development perspective building a supportive innovation ecosystem provides a basis for a shift that will allow an entrepreneurial community to foster local innovation and hence be strategically agile long into the future. In addition, an active innovation ecosystem acts as a meaningful incentive for local small and medium-sized enterprises to grow and become more innovative. Consequently, on a national level, a wellorganized innovation ecosystem not only enables economic growth but also enhances the country's prestige and its international image.

It can be concluded that there is no definitive model to build an optimal local innovation ecosystem and its basic characteristics depend on both the level of economic development and a broad range of politic-legal, socio-cultural and institutional conditions. However, a few general principles can be highlighted that underlie the development of policies aimed at promoting regional innovation ecosystem in the mining sector. First, such innovation ecosystems are dynamic, composite entities. In line with this, as the characteristics of the ecosystem can change over time, the policy approaches need to be periodically revised in accordance with the phase of the ecosystem lifecycle. Second, every innovation ecosystem is unique and there is a wide variety of local and national factors which should be taken into account when devising innovation policy instruments. Finally, it is important to underline the relevance of the integrated approach to creating the local innovation ecosystem that provides a framework for developing holistic solutions aimed at improving the innovation 
performance by combining different dimensions of innovation and integrating various interacting actors in order to develop, adopt and implement innovation.

On the basis of the findings of industry reviews, the main strategic directions for the development of the local innovation ecosystem in the mining industry can be pointed out:

- develop a framework to implement the sectoral ecosystem approach, support platform integration efforts and provide the clarity of direction required for productive strategic partnership and innovation collaboration;

- create a favourable environment for information flow and knowledge exchange between the actors of the innovation ecosystem within the industry, as well as devise a system of incentives to attract technology-based companies and drive innovation;

- establish mechanisms that can be used to enhance investment opportunities for innovation and increase the flexibility of access to financing, including from venture capitalists and institutional funders that have relatively low exposure to the industry;

- design forums and platforms for strategic collaboration which will enable the engagement of key industry players into the innovation ecosystem.

Developing stable collaborative relationships through a coordinated network with technology suppliers, service providers, research and development centers, local communities and other industry players can improve innovation capacity of the mining operators and accelerate the innovation process in the mining sector.

\section{References}

1. E. Hoffecker, Local Innovation: what it is and why it matters for developing economies. D-Lab Working Papers: NDIR Working Paper 01 (Cambridge: Massachusetts Institute of Technology, D-Lab, 2018)

2. O. Granstrand, M. Holgersson. Technovation, 90-91 (2020)

3. A. Kreuzer, K. Mengede, A. Oppermann, M. Regh, Guide for Mapping the Entrepreneurial Ecosystem (Deutsche Gesellschaft für Internationale Zusammenarbeit (GIZ) GmbH, Druckreif, Frankfurt, 2018)

4. A. Aaltonen. Factors Shaping Entrepreneurial Ecosystems and the Rise of Entrepreneurship: A View from Top Management Journals (Demos Helsinki Working Paper, 2016)

5. G. Xu, Y. Wu, T. Minshall, Y. Zhou, Technological Forecasting and Social Change, 136, 208 (2018)

6. J. Steen, S. Macaulay, N. Kunz J. Jackson, Understanding the Innovation Ecosystem in Mining and What the Digital Revolution Means for It. (In Extracting Innovations: Mining, Energy, and Technological Change in the Digital Age. Clifford, M., Perrons, R., Ali, S. and Grice, T. (Eds). New York: CRC Press, 2018)

7. A. Basso, E. Baltar and E. Andonova. Startup Innovation Ecosystems in Southern Europe (European Commission, Brussels, 2018)

8. D. J. Isenberg. The Entrepreneurship Ecosystem Strategy as a New Paradigm for Economy Policy: Principles for Cultivating Entrepreneurship (Babson Entrepreneurship Ecosystem Project, Babson College, Babson Park, 2011)

9. D. J. Isenberg, V. Onyemah, Innovations: Technology, Governance, Globalization, 11:1-2, 60 (2016)

10. C. Mason and R. Brown, Entrepreneurial Ecosystems and Growth Oriented Entrepreneurship (Final Report to OECD, Paris, 2014) 
11. T. Haines. Technology Innovation Management Review, 6:6, 24 (2016)

12. VCI Mining Innovation: State of Play 2015 Survey - Methodology (The University of Western Australia, Minerals and Energy Institute, VCI, 2015)

13. D. Fasnacht. Open Innovation Ecosystems: Creating New Value Constellations in the Financial Services (Springer International Publishing, 2018)

14. H. Bathelt, P. Cohendet, S. Henn, L. Simon. The Elgar Companion to Innovation and Knowledge Creation (Edward Elgar Publishing Ltd, 2017)

15. M. McKelvey, G. Buenstorf A. Broström, Innovation: Organization \& Management, 20:1, 84 (2018)

16. J. Christopher Westland. Global Innovation Management: A Strategic Approach (Macmillan International Higher Education, 2008) 